

\section{Hommage Aux 12 apotres}

Óleo sobre lienzo

$120 \times 120 \mathrm{cms}$

2009

Colección Privada

Universidad Santo Tomás 


\title{
REFLEXIONES SOBRE LA PROBLEMÁTICA DEL ABORTO
}

\section{María Concepción Gorjón Barranco}

Candidata a Doctor en Derecho Penal, Universidad de Salamanca; Diploma de Estudios Avanzados, Universidad de Salamanca (España); Licenciada en Derecho, Universidad de Salamanca (España).

E-mail: mariconcep_1@hotmail.com

\section{Resumen}

La interrupción voluntaria del embarazo, comúnmente conocida como aborto, es un tema de amplio debate en las Democracias del mundo actual. Es un problema relacionado con la sexualidad y con la reproducción pero, a la vez, genera muchos problemas en el ámbito de la moral. Nos centraremos en su estudio en España, aunque al final recurramos a una somera revisión de algunas legislaciones cercanas.

\section{Palabras clave}

Embarazo, aborto, conducta, interrupción.

\begin{abstract}
The voluntary interruption of pregnancy, commonly known as abortion is a subject of much debate in the democracies of today. It is a problem with sexuality and reproduction, but at the same time, causes many problems in the field of morality. We will focus on their study in Spain, but in the end resort to a brief review of some laws nearby.
\end{abstract}

\section{Key Words}

Embarrass, abort, conduct, interruption. 



\section{REFLEXIONES SOBRE LA PROBLEMÁTICA DEL ABORTO*}

María Concepción Gorjón Barranco

La interrupción voluntaria del embarazo, comúnmente conocida como aborto, es un tema de amplio debate en las Democracias del mundo actual. Es un problema relacionado con la sexualidad y con la reproducción pero, a la vez, genera muchos problemas en el ámbito de la moral. Nos centraremos en su estudio en España, aunque al final recurramos a una somera revisión de algunas legislaciones cercanas.

Uno de los grandes factores en consideración es el feminismo, puesto que desde los años setenta y ochenta ha reivindicado los derechos de las mujeres y son muchas las materias que se han convertido en su objeto de estudio ${ }^{1}$. El sucesivo desarrollo de las Políticas de Género en España llevó a la creación del Ministerio de Igualdad en 2008 y, éste ha estimado la necesidad de revisar y actualizar los preceptos del Código Penal encargados de regular el aborto, puesto que éstos, una vez entrado el siglo XXI han visto reducida su capacidad de motivar las conductas tanto de las mujeres como de los médicos. A estos fines resulta interesante resaltar el contenido del Art. 12.1 de la Convención de Naciones Unidas sobre la eliminación de todas las formas de discriminación contra la mujer, en el que se establece que:

\footnotetext{
* El presente artículo es producto del proyecto de investigación doctoral: Estudio Penal Comparado de las legislaciones española y mexicana en materia de Violencia Doméstica y de Género, adelantado por la autora en el Doctorado en Derecho Penal, Universidad de Salamanca. El artículo inicial aborda la problemática del aborto, desarrolla el debate político criminal en el Derecho Comparado (europeo, latinoamericano) y finaliza reflexionando sobre el debate español actual.

1 GIMBERNAT, E.; Diario El Mundo, 10 de julio de 2004 "Los nuevos gestores de la moral colectiva” esgrime como argumento que el Feminismo surgido entre los años 60 y 80 apostó por la despenalización de muchas conductas que favorecían la libertad y capacidad de las mujeres, como es el libre ejercicio del derecho al aborto.
} 
los Estados parte adoptarán todas las medidas apropiadas para eliminar la discriminación contra la mujer en la esfera de la atención médica a fin de asegurar, en condiciones de igualdad entre hombres y mujeres, el acceso a los servicios de atención médica, inclusive los que se refieren a la planificación de la familia.

Para hacer frente al análisis de cualquier problema social se trata, en primer lugar, de ser sensible a los datos existentes. En este ámbito se producen aproximadamente 28 millones de embarazos al año en el mundo, de los cuales casi la mitad son no deseados y el 36\% acaban en aborto ${ }^{2}$. En España en los 24 años trascurridos tras su despenalización parcial se han practicado más de un millón de interrupciones ${ }^{3}$. La observancia de éstos y otros datos que, se expondrán más adelante, nos proporcionará una respuesta más certera a cuál pueda ser el mejor método de regular esta materia de forma garantista y eficaz, sobre todo, desde la perspectiva de las mujeres ${ }^{4}$. Los embarazos no deseados son los que acaban en aborto, de ahí que SILVA SÁNCHEZ defina "aborto provocado" según los parámetros del Derecho Penal del Enemigo como la "destrucción de la vida del concebido y no nacido que, siendo indeseado, es percibido como una carga, o fuente de displacer ${ }^{5}$ ".

El Ministerio de Sanidad y Consumo maneja las siguientes cifras de abortos al año en España

Tabla 1. Abortos en España

\begin{tabular}{|c|c|c|c|c|c|c|c|c|c|}
\hline $\mathbf{1 9 9 8}$ & $\mathbf{1 9 9 9}$ & $\mathbf{2 0 0 0}$ & $\mathbf{2 0 0 1}$ & $\mathbf{2 0 0 2}$ & $\mathbf{2 0 0 3}$ & $\mathbf{2 0 0 4}$ & $\mathbf{2 0 0 5}$ & $\mathbf{2 0 0 6}$ & $\mathbf{2 0 0 7}$ \\
\hline 53.847 & 58.399 & 63.756 & 69.857 & 77.125 & 79.788 & 84.985 & 91.664 & 101.592 & 112.138 \\
\hline
\end{tabular}

Fuente: Ministerio de Sanidad y Consumo

2 Datos recogidos por El País, a 26 de Septiembre de 2008, "España aún teme a la píldora. El uso de la pastilla anticonceptiva es 10 puntos inferior a la media europea- Algunos mitos extendidos en los setenta siguen vivos entre las mujeres españolas."

3 Consultar ESTEBAN, M.; "La modificación de la Ley del Aborto. Una reforma necesaria por el fracaso de una Ley" en Diario médico, a 27 de Octubre de 2008, en http://www.diariomedico.com/ edicion/diario_medico/normativa/es/desarrollo/1178329.html

4 LAURENZO COPELlO, P.; "Otra vez sobre el aborto: el inevitable camino hacia un sistema de plazos”, en Teoría y Derecho: revista del pensamiento jurídico, núm. 3, 2008, p. 236 que nos recuerda que "la legislación no puede permanecer estancada en circunstancias del pasado y ha de acomodarse a las exigencias sociales de cada momento histórico".

5 SILVA SÁNCHEZ, J. M.; "Los indeseados como enemigos. La exclusión de seres humanos del status personae" en Revista Electrónica de Ciencia Penal y Criminología, núm. 9, 1, 2007, P. 5

6 Datos del Ministerio de Sanidad, Tabla EV.5, Informe "Interrupción voluntaria del Embarazo. Datos definitivos correspondientes al año 2007”. 


\section{Una aproximación histórica}

Antigüedad y posterior influencia religiosa. En las sociedades de la Antigüedad se aceptó el aborto como medio de control demográfico, es decir, en Grecia por ejemplo, el propio Aristóteles permitió el aborto cuando el número de nacimientos superase unos topes de población 7 . En Roma también estaba permitido el aborto; incluso el infanticidio, cuyo objetivo era crear generaciones fuertes que sirvieran de manera efectiva al Imperio, bien como mano de obra, bien como fuerza militar. De esa comprensión es heredero hoy el actual Art. 30 del Código Civil español en el que se expresa que "para los efectos civiles, sólo se reputará nacido el feto que tuviere figura humana y viviere veinticuatro horas enteramente desprendido del claustro materno".

Con todo, la influencia de la moral católica llevará a prohibir cualquier política a favor del aborto, al elevar estas conductas a delito en base a una defensa a ultranza del Derecho a la vida, influencia que ha permanecido hasta hace poco más de veinte años. Fueron los países nórdicos y socialistas o comunistas ${ }^{8}$ los que a lo largo del s. XX dieron los primeros pasos a favor de su despenalización. Tras ellos muchos países han reconocido este derecho a las mujeres con menor o mayor amplitud.

Sin embargo con la perspectiva que nos da la historia es más fácil vislumbrar la hipocresía que ha acompañado a la problemática del aborto; para ello baste citar algunos ejemplos; hasta hace no mucho tiempo se ha abusado de políticas tendentes al control de hijos en base a factores de superpoblación y de hambre pero solamente sobre determinadas razas y tribus que se han querido aniquilar ${ }^{9}$, o en base a combatir la miseria que tras la I Guerra Mundial azotó Europa y por la que en 1919 ante la Asamblea Nacional en Alemania se pidió autorización para abortar a mujeres que ya tuviesen tres hijos ${ }^{10}$. O, por el contrario, cuando finalizada la II Guerra Mundial, el número de pérdidas humanas provocó un agudo problema demográfico en Francia por el que se promulgó un Decreto-Ley de 29 de julio de 1939, conocido como el Código de la familia que, a su vez, retocaba en un sentido más restrictivo el art. $317 \mathrm{CP}$ francés ${ }^{11}$ relativo al aborto. En España el marco de incipientes libertades constitucionales

7 CUELLO CALÓN, E.; Tres temas penales: El aborto criminal; el problema penal de la eutanasia; el aspecto penal de la fecundación artificial. Publicaciones del Seminario de Derecho Penal y Criminología de la Universidad de Barcelona, Bosch, Barcelona, 1955, P.9.

8 LANDROVE díAZ, G.; Política Criminal del aborto, Bosch, Barcelona, 1976, P. 50

9 El caso más acuciante y reciente que podemos traer a la memoria nos lo pone de manifiesto la Dra. Asunción VILLATORO y MAGDA ORANICH, en Qué es el aborto, en Biblioteca Salud y Sociedad, Barcelona, 1977, p. 61-63, quienes recuerdan lo acontecido durante el tercer Reich en el que se penaba incluso con pena de muerte a la mujer aria que abortara y sin embargo era obligatorio para la judía.

10 CUELLO CALÓN, E.; Tres temas penales, ob. cit., P.22.

11 LANDROVE DÍAZ, G.; Política Criminal del aborto., ob. cit, P. 118. 
del año 78 propició la liberalización del uso de la píldora anticonceptiva por Ley 45/1978 de 7 de octubre y, finalmente fue la LO 9/1985 de 5 de julio la que permitió la interrupción del embarazo en caso de estar indicado.

Es decir, pareciera que el aborto fue utilizado históricamente como medio de control demográfico y la prohibición de su práctica se enmascaró tras la protección del nasciturus; sin embargo si éste hubiere sido el valor de fondo hubiese merecido protección, le interesase o no, demográficamente al Estado. Por tanto, de ello concluimos que detrás del aborto históricamente no hubo un bien jurídico individual sino un bien disponible por la comunidad.

\section{Causas del fenómeno}

El intento de solucionar un problema social o moral como el aborto a base de Derecho Penal no es sino un desconocimiento de sus causas. Como en muchos otros campos en manos del Derecho Penal, una vez más éste llega mal y tarde en el sentido que la prevención del delito ha fallado. La prevención en este caso llega de la mano de la educación sexual; se trata de abandonar la idea de la existencia de temas tabú en una sociedad en la que el inicio de las relaciones sexuales se produce cada vez a una edad más temprana ${ }^{12}$. Según los datos baremados por el Ministerio de Sanidad y Consumo en 2007, el 13. 79\% de las mujeres que abortaron en ese año eran menores ${ }^{13}$. Ante las cifras, la toma de conciencia frente a la importancia de la prevención se intenta combatir mediante campañas que lleguen a los más jóvenes como la del hip-hop ${ }^{14}$.

Educar a éstos en el uso de métodos anticonceptivos haría que el aborto quedase como un último recurso y su uso se produjere de manera residual. Los factores que pueden influir en el elevado número de abortos que se practican de hoy son: a) que en España pese a la legalización de los medios anticonceptivos, las mujeres aún desconfian de la píldora por todos los mitos sobre sus efectos secundarios, hasta el punto que su uso es diez veces menor a la media europea ${ }^{15}$. La búsqueda de nuevos

12 Según el "Informe Juventud en España 2008”, p. 10, la mayor parte de los jóvenes ha tenido relaciones sexuales a partir de los 18 años, aunque la edad media se sitúa un par de meses antes de los 17 años y desde 2004 se ha reducido en casi un año para ambos sexos, es decir, está casi en los 15 años. Consultar en http://www.injuve.mtas.es/injuve/contenidos.downloadatt.action?id=725387112.

13 Datos del Ministerio de Sanidad, Tabla EV.1, Informe "Interrupción voluntaria del Embarazo. Datos definitivos correspondientes al año 2007"

14 El País, 9 de Diciembre de 2008, "Sanidad recurre al hip-hop en su campaña para reducir los abortos entre los adolescentes. Las interrupciones del embarazo entre las jóvenes aumentaron casi un $17 \%$ en 2007 ".

15 El País, 26 de septiembre de 2008, "España aún teme a la píldora”. 
anticonceptivos está motivada, entre otras causas, por la evidencia de que aún no se ha dado con uno perfecto ${ }^{16}$ "; b) la pérdida de miedo al $\operatorname{SIDA}^{17}, \mathrm{c}$ ) incluso la pérdida del miedo al aborto, cuando en realidad el aborto no puede determinarse como un método anticonceptivo más, sino un último recurso.

Además, con una buena prevención se asegura igualmente la salud de la madre pues la interrupción del embarazo puede llevar aparejados ciertos riesgos como infertilidad o determinadas consecuencias psicológicas; riesgos que incrementan cuanto más avanzado se encuentre el estado de gestación pues también el tipo de operación varía dependiendo del avance del embarazo, siendo más sencilla en las primeras semanas. Ante la falta de prevención ${ }^{18}$ que se ve claramente en el análisis de los datos ya comentados arrojados por el Ministerio de Sanidad, la Presidenta de la Asociación de planificación Familiar de Madrid, Concha Martínez-Perpiñán, propone poner en marcha un Observatorio de Salud Sexual y Reproductiva que elabore planes específicos en este terreno ${ }^{19}$. En este sentido el Estado de Bienestar debe proveer de una batería de medidas para la prevención pero hay opiniones encontradas en el análisis del actual estado del Welfarismo; en palabras de SILVA SÁNCHEZ, en el origen de esta problemática está "el deseo, mientras que el concebido deseado obtiene plena protección jurídica, el no deseado es tildado de enemigo, aunque paradójicamente no nos encontremos en una sociedad de escasez, sino precisamente de bienestar, es objeto de una pretensión de exclusión ${ }^{20 "}$. Por su parte LAURENZO COPELLO ahonda en ese estado de la situación actual y confirma el "deber del Estado de fomentar las condiciones que permitan a las mujeres y a sus parejas alcanzar el plano bienestar en materia reproductiva, sin verse obligadas a retrasar la maternidad o sencillamente a renunciar a ella por obstáculos asociados al declive del Estado del Bienestar- precariedad laboral, dificultades para el acceso a la vivienda y déficit en guarderías, entre otros ${ }^{21}$ ".

Resulta llamativo y por eso merece la pena traerlo a colación, el caso de Holanda que, aunque posee una ley flexible, en realidad "ha logrado reducir la tasa de abortos

16 HERNÁNDEZ RODRÍGUEZ, G.; El aborto en España. Análisis de un proceso socio-politico. Universidad Pontificia Comillas, Madrid, 1992, p. 66

17 El avance de la Medicina en este campo en los últimos años ha sido amplia, sin embargo, todavía es una de las enfermedades más graves a las que una persona pueda hacer frente, ver El País, 10 de junio de 2008, "La pérdida del miedo al SIDA aumenta el contagio al abandonar el sexo seguro. Los casos de sifilis diagnosticados se multiplican por 16 entre 2003 y 2007”.

18 Es de destacar toda la polémica que ha provocado la asignatura de "Educación para la ciudadanía" en la que en el día de ayer el TS se pronunciaba en contra de todos padres y colegios objetores. Todavía queda por ver el recurso que éstos, se prevé, plantearán ante el TC.

19 El País, 3 de Diciembre de 2008 “El aborto se dispara entre los más jóvenes por falta de prevención. España registró 112.000 intervenciones en 2007, e doble que hace diez años".

20 SILVA SÁNCHEZ, J. M.; "Los indeseados como enemigos", ob. cit, P.6.

21 LAURENZO COPELLO, P.: “Otra vez sobre el aborto”, ob. cit, P. 241. 
hasta ser una de las más bajas de Europa gracias a una apuesta por la prevención a través de la educación sexual ${ }^{22}$ ".

Los especialistas de los años ochenta vaticinaban que "la pareja del año 2000 utilizaría métodos anticonceptivos más sofisticados y seguros" pero como vemos los datos no se corresponden con tales augurios. Los embarazos no deseados, y por tanto el número de abortos en el s. XXI no sólo se estanca, sino que crece, por lo que aunque la medicina nos regale soluciones, en realidad no se utilizan esos avances.

\section{Un juego de intereses contrapuestos}

Constitucionalmente son dos, en principio, los intereses que entran en conflicto cuando hablamos de aborto; el derecho a vivir del nasciturus y el derecho de la madre a decidir si quiere o no seguir adelante con la gestación.

Esencial en el debate ha sido desgranar el sentido del art. 15 de la $\mathrm{CE}^{23}$, en el que muchos ven un tope infranqueable para la Política Criminal, pues el significado de la expresión "TODOS tienen derecho a la vida" ha tenido varias interpretaciones, pero tomaremos aquí de referencia la doctrina emanada de la STC 53/1985 de 11 de abril. Nuestro TC se pronunció sobre el recurso de inconstitucionalidad interpuesto ante el Proyecto de Ley Orgánica de reforma del art. 417 bis CP de 1983, que acepta la vida del nasciturus como bien constitucionalmente protegido ${ }^{24}$ pero sin elevarlo a la categoría de persona ${ }^{25}$ : "el nasciturus está protegido por el art. $15 \mathrm{CE}$, aún cuando no permite afirmar que sea titular del derecho fundamental ${ }^{26}$ ".

En cuanto a la protección de los intereses de la mujer, la STC estableció que

"la dignidad está reconocida a todas las personas con carácter general, pero cuando el intérprete constitucional trata de concretar este principio no puede ignorar el hecho obvio de la especialidad de la condición femenina y la concreción de los mencionados derechos en el ámbito de la maternidad, derechos que el Estado debe respetar y a cuya efectividad debe contribuir, dentro de los límites impuestos por la existencia de otros derechos y bienes asimismo reconocidos por la Constitución ${ }^{27 "}$.

22 El País, 24 de Julio de 2008 “Abortar sin explicaciones es un derecho? La propuesta de una ley de plazos, que daría cobertura a un $90 \%$ de las interrupciones de embarazo, divide a los juristas- La doctrina de 1985 del Constitucional puede dificultar la reforma legal".

23 Art. 15 CE: "Todos tienen derecho a la vida y a la integridad física y moral, sin que, en ningún caso, puedan ser sometidos a tortura ni a penas o tratos inhumanos o degradantes".

24 Fundamento Jurídico núm. 7, STC (Pleno), Sentencia núm. 53/1985 de 11 de abril.

25 Para SILVA SÁNCHEZ, J. M.; "Los indeseados como enemigos", ob. cit., P. 6 "el enemigo es objeto de una pretensión de exclusión: La privación de status personae es únicamente el eslabón intermedio del proceso, pues conlleva la negación de la condición de sujeto de derechos (y, en particular, del derecho a la vida) a partir de la que es fácil excluir."

26 Fundamento Jurídico núm. 5, STC (Pleno), Sentencia núm. 53/1985 de 11 de abril.

27 Fundamento Jurídico núm. 8, STC (Pleno), Sentencia núm. 53/1985 de 11 de abril. 


\section{El conflicto de esos intereses en el Derecho Penal: el estado de necesidad}

Con carácter general la mayoría de la doctrina defiende hoy un bien jurídico en el aborto que poco tiene que ver ya con el intento de control demográfico. En este sentido toma más fuerza la vida del nasciturus, sobre todo a raíz de la STC de 1985. La ubicación sistemática en el Libro II del CP dentro de los delitos contra la vida humana dependiente supone un criterio no desestimable y, útil desde el punto de vista de la interpretación teleológica. Así, la mayor parte de la doctrina estima como bien jurídico la vida del feto, o la vida en gestación ${ }^{28} \mathrm{o}$ en formación ${ }^{29} \mathrm{o}$ la vida dependiente y algunos introducen el requisito de la viabilidad extrauterina ${ }^{30}$.

La problemática gira en torno a la idea de cuándo o en qué momento en concreto comienza la vida, habrá que resolver primero esta cuestión previa y, de esta manera, determinar cuándo su existencia entra en conflicto con los intereses de la madre. Las respuestas que históricamente se han dado se exponen a continuación; 1) El momento de la Animación: que es una expresión filosófica tomada de la Escolástica Tomista dada en respuesta a la falta de estudios médicos de la época y que consistía en la unión del cuerpo con el alma, momento en el que comenzaba la vida; cuando se dotaba de alma al embrión ${ }^{31}$. Es decir, el feto no era tan sólo una parte del cuerpo de la madre, sino un ser dotado de alma ${ }^{32}$. 2) La Fecundación: con los estudios desarrollados en Medicina a lo largo del siglo pasado, se demostró que la unión de las células sexuales o gametos daba lugar al huevo fertilizado ${ }^{33}$. En este sentido se expresa RODRÍGUEZ DEVESA, afirmando que "la Constitución habla de la vida de los seres humanos en el sentido biológico de la palabra, y ésta comienza, sin lugar a dudas, con la fecundación del óvulo y concluye con la muerte ${ }^{34}$ ". Y por último

28 LAURENZO COPELlO, P.; El fundamento de las indicaciones en el aborto, ed. Universidad Complutense de Madrid, 1990, p. 256.

29 Para la mayoría de la doctrina, éste es el auténtico bien jurídico que se encuentra detrás de la interrupción voluntaria del embarazo junto con otros relativos a la madre, así CUELLO CALÓN, E.; Tres temas penales, ob. cit., P. 47, al igual que COBO DEL ROSAL, M.; CARBONELL MATEU, J. C.; "El aborto en el Código Penal Español" en Criminología y Derecho Penal al servicio de la reforma,.ob. cit.. p. 674.

30 LASCURAÍN SÁNCHEZ, J. A.; "Del Aborto” en RODRÍGUEZ MOURULLO, G. (Director) y JORGE BARREIRO, A.; (Coord), Comentarios al Código Penal, ed. Civitas, Madrid, 1997, P.422.

31 VILLATORO, A.; y ORANICH, M.; ¿Qué es el aborto, ob. cit., p. 11 y 60

32 CUELLO CALÓN, E.; Tres temas penales., ob. cit., P. 11

33 Puede consultarse en http://ciencia.glosario.net/biotecnologia/c\%E9lulas-sexuales-10060.html.

34 RODRÍGUEZ DEVESA, J. M.; y SERRANO GÓMEZ, A.; Derecho Penal Español. Parte Especial, $17^{a}$ edición, Dykinson, Madrid, 1994, p.103. En el mismo sentido se pronuncia CALVO-ÁLVAREZ, J.; Aborto y Derecho. Consideraciones críticas en torno a la doctrina del Tribunal Constitucional, Instituto de Ciencias para la familia, Pamplona, 1997. P. 39 reconoce que el nasciturus "desde el mismo momento del inicio de la gestación, es ya un individuo humano, es, por eso mismo, y en el sentido recientemente indicado, ya una persona. No se trata de concederle ese carácter, si no de reconocer jurídicamente lo que está siendo." 
3) La Anidación, que es un momento posterior a la fecundación en el proceso del embarazo que se determina en la fijación (anidación) del óvulo ya fecundado en el útero materno ${ }^{35}$. A partir de este momento tasado según los expertos desde los catorce días de la fecundación ${ }^{36}$, deja su denominación de embrión y pasa a la de feto en donde comienzan los latidos del corazón y la actividad cerebral ${ }^{37}$. Establecer cualquier momento anterior supondría considerar aborto todos aquellos óvulos fecundados en un laboratorio y que nuca llegan a terminar el proceso, lo cual llevaría incluso a prohibir las técnicas de reproducción asistida ${ }^{38}$.

En España el debate sobre la posible despenalización del aborto en estos casos indicados no se había plasmado a nivel legislativo, pero en los países germánicos ya existía impunidad para el caso del aborto terapéutico desde finales del s. XIX ${ }^{39}$. No es hasta la LO 9/1985 cuando el aborto se despenaliza de manera parcial en España, es decir, sigue penado con carácter general excepto en tres supuestos sujetos a una serie de requisitos; tres excepciones que vendrían a fundamentarse en un conflicto de intereses en los que en base a un estado de necesitad justificante o exculpante según el caso, quedaría impune la mujer que se sometiere a una interrupción del embarazo. Para COBO DEL ROSAL y CARBONELL MATEU se trataría de "auténticas causas de justificación de la conducta típica fundamentadas en el conflicto de intereses ${ }^{40}$ " $\mathrm{y}$, visto desde un contexto justificante DÍEZ RIPOLLÉS se refiere al sistema de indicaciones como una peculiar ponderación de intereses en la que los bienes a ponderar son además de los propios del nasciturus y la madre, otros denominados "sociales-instrumentales" como son poder garantizar una ejecución adecuada o poder proveer de ayudas económicas a las mujeres que se sometan a este proceso ${ }^{41}$. Según lo dispuesto en el Fundamento Jurídico núm. 11 de la STC 53/1985 ${ }^{42}$ : a) la indicación terapéutica se encuadra en el estado de necesidad justificante en el que el valor preponderante es la salud y la vida de la madre por encima de la vida del nasciturus,

35 Téngase en cuenta que uno de los medios anticonceptivos legalizados en España, el famoso DIU, funciona impidiendo la anidación del huevo fecundado en el útero materno, por lo que estimar la fecundación como inicio de la vida implicaría la práctica delictiva de estos abortivos.

36 MUÑOZ CONDE, F.; Derecho Penal. Parte Especial. Décimo sexta edición revisada y puesta al dia, Tirant Lo Blanch, Valencia, 2007, P.87

37 COBO DEL ROSAL, M.; CARBONELL MATEU, J. C.; "El aborto en el Código Penal Español” en Criminología y Derecho Penal al servicio de la reforma., ob. cit., p. 675

38 MUÑOZ CONDE, F.; Derecho Penal. Parte Especial., ob. cit., P.87

39 LAURENZO COPELlO, P.; El fundamento de las indicaciones en el aborto., ob. cit., p.862, conclusión $1^{\circ}$

40 COBO DEL ROSAL, M.; CARBOnEll MATEU, J. C.; "El aborto en el Código Penal Español” en Criminología y Derecho Penal al servicio de la reforma., ob. cit., p.687.

41 DÍEZ RIPOLLÉS, J. L.; "El aborto en el Código Penal Español" en Criminología y Derecho Penal al servicio de la reforma. Libro Homenaje al Profesor Antonio Berinstáin, Instituto Vasco de Criminología, San Sebastián, 1989. p. 708-709.

42 Al igual que RODRÍGUEZ DEVESA, J. M.; y SERRANO GÓMEZ, A.; Derecho Penal Español., ob. cit., p. 91. 
pues "si la vida del nasciturus se protegiera incondicionalmente, se protegería más la vida del no nacido que la vida del nacido" al igual que la prevalencia de la salud de la madre no es inconstitucional porque "la exigencia del sacrificio importante y duradero de su salud bajo la conminación de una sanción penal puede estimarse inadecuada". b) la indicación eugenésica "incluye verdaderos casos límite" y se fundamenta en que "el recurso a la sanción penal entrañaría la imposición de una conducta que excede de la que normalmente es exigible a la madre y a la familia”. c) el fundamento de la indicación ética estaría en la no exigibilidad de otra conducta a la mujer que quiere abortar tras ser el fruto de esa concepción resultado de un delito de violación, pues "obligarla a soportar las consecuencias de un acto de tal naturaleza es inexigible".

En realidad al comparar las penas que el legislador penal depara para el homicidio (art. 138 CP, 10-15 años) o las lesiones (art. 147.1 CP, seis meses a tres años), con las que le corresponde al aborto consentido (art. 145.1, uno a tres años) comprobamos que para el caso de muerte o incluso de lesiones a la madre se prevé más pena que en el tipo de aborto. Recurrir a la propia ley penal para descubrir a qué hechos el legislador le ha dado mayor valor fue la solución dada por la Sentencia del Tribunal Supremo alemán de 11 de marzo de $1927^{43}$.

\section{EL SISTEMA DE INDICACIONES ACTUALMENTE RECOGIDO EN EL CÓDIGO PENAL Y SU REFLEJO SOCIAL}

El sistema de indicaciones sigue en vigor en el Código Penal por Disposición Derogatoria Única del Código Penal, vestigio del anterior Texto Refundido del CP -73 en que se encuadra el art. 417 bis CP, en el que se regulan de manera expresa las indicaciones existentes y cuyo origen se remonta a la citada LO 9/1985 de 5 de julio.

Art. 417 bis:

"1. No será punible el aborto practicado por un médico o bajo su dirección, en centro o establecimiento sanitario, público o privado acreditado y con consentimiento expreso de la mujer embarazada cuando concurra consentimiento expreso de la mujer embarazada, cuando concurra alguna de las circunstancias siguientes:

$1^{a}$. Que sea necesario para evitar un grave peligro para la vida o la salud física o psíquica de la embarazada y así conste en un dictamen emitido con anterioridad a la intervención por un médico de la especialidad correspondiente, distinto de aquel por quien o bajo cuya dirección se practique el aborto.

43 Para más información sobre el caso y la Sentencia alemana, consultar LAURENZO COPELLO, P.; El fundamento de las indicaciones en el aborto., ob. cit, P. 118 
En caso de urgencia por riesgo vital para la gestante, podrá prescindirse del dictamen y del consentimiento expreso.

$2^{a}$. Que el embarazo sea consecuencia de un hecho constitutivo de delito de violación del art. 429, siempre que el aborto se practique dentro de las doce primeras semanas de gestación y que el mencionado hecho hubiese sido denunciado.

$3^{a}$. Que se presuma que el feto habrá de nacer con graves taras físicas o psíquicas, siempre que el aborto se practique dentro de las veintidós primeras semanas de gestación y que el dictamen, expresado con anterioridad a la práctica del aborto, sea emitido por dos especialistas de centro o establecimiento sanitario, público o privado, acreditado al efecto, y distinto de aquel por quien o bajo cuya dirección se practique el aborto.

2. En los casos previstos en el número anterior, no será punible la conducta de la embarazada aun cuando la práctica del aborto no se realice en un centro o establecimiento público o privado acreditado o no se hayan emitido los dictámenes médicos exigidos".

Con carácter general, los requisitos comunes a toda indicación se resumen en: a) la existencia de un conflicto de intereses entre la vida en formación y la vida o salud de la madre en algunos casos, o su libertad o el derecho al libre desarrollo de la personalidad.; b) que están sujetas a un determinado plazo, como más detalladamente se dispone a continuación; c) que requieren de un consentimiento previo de la mujer embarazada, excepto en el caso de la indicación terapéutica en que el consentimiento puede ser tácito ${ }^{44} ; \mathrm{y} d$ ) según la regulación administrativa en la materia su práctica debe llevarse a cabo en centros acreditados y bajo la dirección de un médico según lo dispuesto por RD 2409/1986 de 21 de noviembre.

Indicación Terapéutica o médica, art. 417 bis, $1,1^{\circ} \mathrm{CP}$ : Se refiere al conflicto que se establece entre la vida del nasciturus y la salud o la vida de la mujer embarazada. Esta indicación se constituye en un estado de necesidad justificante propiamente, pues es el propio legislador el que así lo determina al no establecer un plazo límite para poder llevar a cabo la interrupción, dando en este sentido prevalencia en todo caso a la vida de la madre sobre la del nasciturus ${ }^{45}$, es decir, un estado de necesidad de bienes jurídicos no equivalentes. Los requisitos específicos establecidos son: 1) que se trate de evitar un grave peligro para la vida o la salud física o psíquica de la embarazada. 2) un dictamen médico distinto de aquel que va a practicar el aborto. Se han producido fuertes críticas por parte de los sectores más conservadores porque a través de esta Indicación se introducirán comportamientos más propios de la llamada

44 ROMEO CASABONA, C. M.; Estudios de Derecho Penal. Los delitos contra la vida y la integridad personal y los relativos a la manipulación genética, Comares, Granada, 2004, P.177

45 LAURENZO COPELlO, P.; El fundamento de las indicaciones en el aborto., ob. cit., p. 876 conclusión 44. 
indicación económico-social en la que se alegarían motivos como la falta de recursos económicos para poder justificar un aborto46. Hecho que para GONZÁLEZ RUS "aparte de una descarada burla de las previsiones legales, supondría un sin sentido político-criminal, pues al no requerir el aborto terapéutico plazo alguno dentro del que haya de realizarse, se dará entrada, realmente, al aborto libre47'.

Indicación Ética o criminológica, art. 617 bis 1, 2 CP. Algunos autores prefieren el término criminológico, como por ejemplo, ROMEO CASABONA porque "la denominación <ética $>$ resulta ciertamente equívoca y poco afortunada ya que no se refiere al aborto en cuanto tal, sino a la situación que conduce a él ${ }^{48}$ ". Del mismo modo LAURENZO COPELLO prefiere la denominación de criminológica porque la de <ética > remite a la salvaguarda de la "honra", que es una cuestión que no tiene cabida en el Derecho Penal moderno ${ }^{49}$.

El embarazo aquí se manifiesta como resultado de un delito de violación del anterior art. 429 CP- 73, hoy ubicado en el art. 179 CP. En este caso el conflicto se produce entre la vida en gestación y la libertad de la mujer a la que se le impone un proceso de embarazo tras una violación y, por tanto, se afecta a su derecho de libre decisión. Obligar a una mujer a sufrir las consecuencias de una violación sin su consentimiento conlleva una doble victimización; una por la violación y la otra por la imposición de una maternidad no buscada y no querida. Los requisitos específicos que han de confluir son; 1) que el embarazo sea constitutivo de un delito de violación, 2) que se lleve a cabo en el plazo de las doce primeras semanas y 3) que haya una denuncia previa.

Indicación Eugenésica ó embriopática ${ }^{50}$ art. 617 bis1. $3^{\circ} \mathrm{CP}$. El conflicto de intereses se debate en este caso entre la vida en formación del feto y la libertad de la madre o, incluso el libre desarrollo de su personalidad. En este caso, se trata de no sobrecargar de trabajo a la madre con un niño que va a necesitar atenciones especiales con la traducción económico-social que ello conlleva. Los requisitos específicos son; 1) presunción de que el feto vaya a nacer con graves taras físicas o psíquicas. 2)

46 Consultar en el diario ABC, 25 de noviembre de 2008, "El Instituto de Política Familiar ve en el aborto $<$ la principal causa de violencia contra la mujer. Alerta de que ya se superan los 110.000 casos anuales>, el Presidente del Instituto de Política Familiar, Eduardo Hertfelder de Aldecoa criticó los "coladeros" que existen en la aplicación de la ley española <porque el tercer supuestoriesgo psicológico para la madre-no conoce ningún tipo de límites>,

47 GONZÁlez RUS, J. J.; "El Aborto", en COBO DEL ROSAL, M.; (Coord.), Derecho Penal Español, ob. cit. P. 134

48 ROMEO CASABONA, C. M.; El Derecho y la bioética ante los límites de la vida humana. Ed. Centro de Estudios Ramón Areces. Madrid, 1994, P. 346.

49 LAURENZO COPELLO, P.; El fundamento de las indicaciones en el aborto, ob. cit., p. 411 nota el pie núm. 473.

50 ROMEO CASABONA, C. M.; Estudios de Derecho Penal., ob. cit., P. 183, Denominación seguida por GONZÁlEZ RUS, J. J.; "El Aborto", en COBO DEL ROSAL, M.; (Coord), Derecho Penal Español, ob. cit. P. 123 y 135. 
que se lleve a cabo durante las veintidós primeras semanas y 3) que existan dos dictámenes de dos especialistas distintos de quien va a practicar el aborto.

El problema en el cumplimiento de esos requisitos específicos en cada uno de estos supuestos indicados es, que se han visto ampliados a la hora de su puesta en práctica, pues como afirma MUÑOZ CONDE, “el que esas excepciones sean más o menos amplias, dependerá más de la realidad social que de la propia normativa jurídico-penal existente ${ }^{51}$ " que es lo que en los últimos años ha ocurrido. Para evitar tener una normatividad vulnerable y vulnerada la opción que se está baraja actualmente es el estudio de la implementación del sistema de Plazos en nuestro país, trabajo que actualmente se lleva a cabo en el Parlamento como se analizará más adelante.

En definitiva, se asiste a un gran debate sobre todo social debido al alarmismo generado por los medios de comunicación al hacer público el número de mujeres que hacen uso de las prácticas abortivas, sobre todo, en clínicas privadas ${ }^{52}$. La polémica se ha avivado en los últimos años sobremanera con los casos de las clínicas del Doctor Morín en Barcelona ${ }^{53}$ y del centro Isidora en Madrid al documentarse una serie de casos en los que se habrían practicado abortos en fetos en muy avanzado estado de gestación en esas clínicas, sobre todo en base al "grave peligro para la vida o la salud física o psíquica de la mujer", que resulta una expresión indeterminada y que puede llevar a justificar un aborto en un estado muy avanzado de la gestación. La percepción generada alrededor del aborto en el último año es la relativa facilidad con la que médicos y mujeres pueden burlar la ley a través de una de las indicaciones propuestas en el art. 417 bis CP. Es el caso, como se verá, de la indicación terapéutica o médica que no exige límites temporales en el que ejercitar la interrupción y fácil de conseguir con un dictamen médico que asegure un riesgo psicológico para la madre.

\section{Debate político-criminal actual}

Una visión de Derecho Comparado Europeo. La represión penal del aborto provocado no ha dado suficiente seguridad jurídica ni a las mujeres ni a los médicos que tras algunos procesos de interrupción del embarazo se han visto llamados a la justicia. Razón por la que en los últimos años se ha llevado a cabo un movimiento de reforma en pro de la liberalización de estas conductas en muchos países

"que va desde dejar a la mujer embarazada la decisión de poder interrumpir el embarazo impunemente, hasta el reconocimiento de un repertorio más o menos extenso, por ejemplo la práctica legal previo examen de una Comisión de expertos

51 MUÑOZ CONDE, F.; Derecho Penal. Parte Especial., ob. cit., P. 86

52 Según los datos recabados, sólo el 3\% de las interrupciones voluntarias del embarazo se realizan en la actualidad en los hospitales públicos, según datos de El País de 22 de Abril de 2008, "Un grupo de expertos en bioética aboga por el aborto libre hasta las 14 primeras semanas".

53 El País, 19 de Diciembre de 2007 "Cierran las clínicas de Morín en Barcelona. La guardia civil investiga si hubo más abortos ilegales tras las detenciones". 
que legitiman el aborto ${ }^{54 ”}$.

Países como Reino Unido cuentan en su legislación con un sistema de indicaciones pero en el que existe un supuesto más que en la actual ley española y es el "conflicto personal" de la madre ${ }^{55}$ que permite el aborto por este motivo hasta las 24 semanas. Sin embargo muchos de los países europeos han optado ya por una ley de plazos, así el caso de Holanda es hoy el más permisivo y avanzado de Europa, pues permite el aborto libre hasta las 24 semanas $^{56}$ sin necesidad de alegar ninguna causa. Caso similar al anterior es el sueco que permite a la mujer interrumpir libremente su embarazo hasta las primeras 18 semanas $^{57}$ y el caso francés ${ }^{58}$ que permite el aborto libre hasta las 12 primeras semanas. Incluso la regulación en Italia es más permisiva con el embarazo que la española actual ${ }^{59}$. En todos ellos se da un plazo libre sin perjuicio de poder practicar un aborto en las semanas posteriores siempre y cuando concurran situaciones de peligro para la madre, o se presuman graves taras en el feto u otras, en definitiva, que concurran situaciones indicadas.

Por tanto, el sistema del plazo está implementado en casi todos los Estados de nuestro entorno, en

"todos los de la Unión Europea, salvo Polonia, Chipre y Luxemburgo que siguen un sistema de indicaciones e Irlanda, Malta y los microestados de Andorra, Mónaco y San Marino en donde se prohíbe en todo caso la interrupción voluntaria del embarazo ${ }^{60 "}$.

Dentro de los países que acogen el sistema de plazo, por lo general son las doce semanas el plazo establecido para el libre aborto,

"hacen excepción, además de Portugal y Eslovaquia que reducen el plazo a diez semanas, Suecia, Holanda y Rumanía (catorce en este caso, como se propone en el Anteproyecto) ${ }^{61} "$,

en Gran Bretaña se ha reducido de 28 a 24 semanas, y en el caso de Francia a partir de 2001, en vez de las 12 semanas con las que se contaba, toman de referencia las dos semanas a partir de la primera falta de la madre ${ }^{62}$.

54 RODRÍGUEZ DEVESA, J. M.; y SERRANO GÓMEZ, A.; Derecho Penal Español., ob. cit., P.97.

55 Diario ABC, 7 de Septiembre de 2008, "La nueva ley del aborto que viene".

56 Consultar en RTV noticias, disponible en http://www.rtve.es/noticias/20080904/abortoeuropa/150626.shtml.

57 Ibídem.

58 El país galo ha sido uno de los más progresistas en la regulación del aborto, para más información, consultar el estudio que hace sobre este país LANDROVE DÍAZ, G.; La Política Criminal del aborto, ob. cit., P. 116 y ss, haciendo un estudio evolutivo desde el represivo Código Penal francés de 1810 hasta su vanguardista regulación alcanzada en 1975.

59 En Italia la decisión de abortar es libre para la madre durante los noventa primeros días de la gestación. Consultar en RTV noticias http://www.rtve.es/noticias/20080904/aborto-europa/150626. shtml.

60 Datos que se destacan del Dictamen de la Comisión permanente del Consejo de Estado aprobado por unanimidad en Sesión celebrada el 17 de septiembre de 2009, p. 20.

61 Dictamen de la Comisión permanente del Consejo de Estado aprobado por unanimidad en Sesión celebrada el 17 de septiembre de 2009, p. 31

62 Dictamen de la Comisión permanente del Consejo de Estado aprobado por unanimidad en Sesión celebrada el 17 de septiembre de 2009, p. 31 
Caso excepcional es el regulado en Canadá pues no existe restricción alguna en la práctica abortiva, (es por tanto, una cuestión de mera práctica médica) ${ }^{63}$ sería inviable hoy en nuestro país, pues todavía tiene gran calado la doctrina de la STC del aborto de 1985 en la que se reconocía cierto valor constitucional a la vida del nasciturus. Según LAURENZO COPELLO el modelo actual alemán sería el modelo más fácil de implementar en el sistema español ${ }^{64}$; es el modelo del asesoramiento y consiste en una variante del sistema del Plazo en la que se permite interrumpir la gestación en sus doce primeras semanas pero, en el que la mujer debe someterse a una fase previa de asesoramiento obligatorio encaminado a la continuidad del embarazo.

Una visión de Derecho Comparado Latinoamericano. Se hace eco en este apartado de los debates llevados a cabo en muchos países de Latinoamérica es así que en los últimos años, en muchos de estos países se ha intentado regular también esta controversia entre el nasciturus y las mujeres. En constituciones como la paraguaya se ataja el problema de raíz, es decir, en el art. 4 de 1992 del Paraguay se establece que el derecho a la vida es inherente a la persona humana. Se garantiza su protección, en general desde la concepción. Queda abolida la pena de muerte. Toda persona será protegida por el Estado en su integridad física y psíquica, así como en su honor y en su reputación. La Ley reglamentará la libertad de las personas para disponer de su propio cuerpo sólo con fines científicos o médicos.

Sorprende la disparidad de legislaciones en Latinoamérica pues, en México, en concreto la normativa relativa al DF (a la Ciudad de México) ya cuenta con un sistema de plazos desde 2007, que logra a través de un Decreto publicado en la Gaceta Oficial del Distrito Federal con fecha de 26 de abril de $2007^{65}$.

Sin embargo, el intento de una ley de plazos en Uruguay, por ejemplo no tuvo salida debido a que el Presidente Tabaré Vázquez tumbó la parte de la propuesta relativa a la Ley de Salud sexual y reproductiva que despenalizaba el aborto ${ }^{66}$.

63 Es el modelo que propone la Coordinadora Estatal de Mujeres Abogadas en representación de 150 abogadas que piden que el aborto no sea delito en ninguno de los casos y que se deje en manos del libre derecho de las mujeres de decidir, para más información consultar en "Ni ley de plazos, ni de supuestos: despenalización. La coordinadora estatal de Mujeres Abogadas pide que se supriman del Código Penal los artículos que persiguen el aborto y se reconozca el derecho de la mujer a decidir", en Ameco Press. Información para la igualdad a 5 de Diciembre de 2008, http://www.amecopress. net/spip.php?article1970.

64 Para más información consultar LAURENZO COPELLO, P.; Otra vez sobre el aborto, ob. cit., P.242-243.

65 Para más información, consultar ISLAS DE GONZÁLEZ MARISCAL, O.; "Evolución del aborto en México", en Boletín Mexicano de Derecho Comparado, nueva serie, año XLI, núm. 123, Septiembre- Diciembre de 2008, p. 1338

66 El Mundo, 14 de noviembre de 2008, "La que hay es de 1938 y castiga con cárcel la práctica. El Presidente uruguayo veta la ley que despenaliza el aborto". http://www.elmundo.es/ elmundo/2008/11/14/internacional/1226617384.html 
En Perú la Comisión especial revisora del código penal peruano del Congreso debate en estos meses los temas relativos a la legalización del aborto y la eutanasia, que establece como posible solución la interrupción del embarazo en casos de violación o malformaciones del feto ${ }^{67}$.

De Colombia es interesante destacar la Sentencia C-355/06 de 10 de mayo de 2006 de la Sala Plena de la Corte Constitucional atiende a las demandas de inconstitucionalidad vertidas sobre los artículos 122, 123 y 124 de la Ley 599 de 2000 Código Penal, dicha Corte tras hacer un repaso por muchas de las legislaciones que ya han aceptado la regulación del aborto, establece para Colombia la exequibilidad del art. 122 del código penal (que refleja el aborto producido con el consentimiento de la mujer), siempre que con la voluntad de la mujer la interrupción del embarazo se produzca en tres casos concretos; cuando el embarazo sea un peligro para la salud de la mujer, cuando exista grave malformación del feto, cuando el embarazo sea producto de una violación previamente denunciada, es decir, los típicos casos del sistema de indicaciones. Esta nueva doctrina sentada por la Corte Constitucional necesita llegar a ser conocida, es por ello que se pide a todas las instituciones que proclamen el sistema de indicaciones y tengan informada a la población ${ }^{68}$.

\section{El debate actual español}

La propia Exposición de Motivos del Código Penal de 1995 remite a la Ley especial las normas reguladoras de la despenalización de la interrupción voluntaria del embarazo, pero como hemos visto la actual Ley del aborto de 1985 ha quedado obsoleta, incapaz de motivar el comportamiento de muchas mujeres según demuestran los datos puestos de manifiesto anteriormente. Además, según esos datos el $88,15 \%$ de las interrupciones se produce en las primeras 12 semanas $^{69}$, por lo que permitir una interrupción libre en esas primeras semanas de gestación daría al traste con la inseguridad jurídica que pudiere provocar la actual justificación de las indicaciones. De esta manera se regularía ese supuesto "fraude de ley" que muchos estiman en la alegación del supuesto de grave riesgo para la salud o vida materna. En palabras de Cristina Almeida las mujeres se ven y se han visto obligadas a acudir a este supuesto y ha habido mujeres cuya situación se ha pretendido revisar a posteriori

67 Diario El País, 9 de octubre de 2009, "El Congreso peruano debate legalizar el aborto y la eutanasia. Grupos pro-vida critican la idea y los partidarios celebran retomar un tema tabú".

68 Diario El País, 22 de octubre de 2009, "La Iglesia rechaza informar sobre el aborto en las escuelas de Colombia. La Corte Constitucional obliga al Gobierno a poner sobre aviso a los adolescentes"

69 Datos del Ministerio de Sanidad y Consumo, Informe "Interrupción Voluntaria del embarazo. Datos definitivos correspondientes al año 2007.” Tabla EV.4 Distribución porcentual según tipo de centro, semanas de gestación, etc., según la cual en 2007 fueron un 62, 84\% los embarazos se producen en las primeras 8 semanas y el 25,31\% durante las semanas 9-12. 
para comprobar si se ajustaba en realidad a esa indicación de grave riesgo para la salud psíquica o no, lo que supone esto una grave desprotección jurídica para ellas ${ }^{70}$.

Con el inicio de la nueva Legislatura del Gobierno socialista en 2008 arrancaron unos trabajos en la Comisión de Igualdad del Congreso de los Diputados, ayudada por una Subcomisión Parlamentaria ${ }^{71}$ y un Comité de Expertos juristas y médicos de reconocido prestigio, cuyo cometido es la redacción de una nueva ley ${ }^{72}$. El debate está asegurado y será difícil el consenso pues se pondrán sobre la mesa posturas totalmente contrapuestas; mientras el partido en el Gobierno apuesta por una ley de plazos, el partido de la oposición alega la inconstitucionalidad de esa posibilidad.

Proyecto de Ley orgánica de Salud Sexual y Reproductiva de la Interrupción voluntaria del Embarazo, que toma en cuenta desde la vida en gestación, hasta los derechos de la madre, incluidos por supuesto todos aquellos referidos a datos de carácter personal. En ella se plantea un sistema de plazos (aborto libre hasta las primeras 14 semanas), sin perjuicio de que subsistan las indicaciones pasadas las catorce semanas, es decir, hasta las 22 semanas si existiere un grave riesgo para la vida de la madre o graves anomalías en el feto y sin límites si hay malformaciones incompatibles con la vida del feto o este padece una "enfermedad de extrema gravedad e incurable ${ }^{73}$ ".

\section{Nueva hoja de ruta en España: hacia un sistema de plazos}

La STC de 1985 afirma que la

"protección que la Constitución dispensa al nasciturus implica para el Estado con carácter general dos obligaciones: la de abstenerse de interrumpir o de obstaculizar el proceso natural de gestación, y la de establecer un sistema legal para la defensa de la vida que suponga una protección efectiva de la misma y que, dado el carácter fundamental de ésta, incluya también como única garantía, las normas penales. Ello no significa que dicha protección haya de revestir

70 Según El País, 24 de Julio de 2008, “'Abortar sin explicaciones es un derecho? La propuesta de una Ley de plazos, que daría cobertura a un $90 \%$ de las interrupciones de embarazo, divide a los juristas- La doctrina de 1985 del Constitucional puede dificultar la reforma legal", en donde se afirma que en 2006 el 96,98\% de los abortos se hicieron bajo el supuesto de riesgo para la salud materna.

71 En la Subcomisión que estudia la Propuesta de Reforma hay profesionales propuestos por todos los partidos políticos, por ejemplo, Benigno Blanco, a propuestas del PP, que es el Presidente del Foro Español de la Familia, o Justa Montero, a propuestas de IU, Coordinadora de Organizaciones Feministas, o Marisa Sotelo de la Fundación Mujeres, propuesta por el PSOE para más información consultar El País, 11 de Noviembre de 2008 "Benigno Blanco: <El aborto legal es Violencia de género>”, para el Presidente del Foro Español de la Familia la despenalización del aborto es una "solución machista" que hace al hombre "irresponsable de su conducta sexual".

72 El contenido de la nueva ley puede consultarse en http://www.hazteoir.org/files/Proyecto\%20 de\%20Ley\%20Cjo\%20Ministros\%20260909.doc

73 El País, 4 de diciembre de 2009, "Las menores podrán abortar solas si alegan un conflicto familiar. El PSOE ofrece al PNV una salida para el punto más polémico de la ley. Se exigirá una declaración del padre o tutor, pero la mujer podrá eludirlo". 
carácter absoluto; pues como sucede en relación con todos los bienes y derechos constitucionalmente reconocidos, en determinados supuestos puede y aún debe estar sujeta a limitaciones ${ }^{74}$."

Al no revestir carácter absoluto, la protección de la vida tiene unas limitaciones. Por eso se ha estimado como punto de partida la definición de aborto que facilita la Organización Mundial de la Salud (OMS) y que lo conceptualiza como "un proceso por el cual el embarazo es terminado cuando el feto es viable ${ }^{75}$ ". Opción que viene a complementar el Observatorio de Bioética y Derecho de la Universidad de Barcelona que ha elaborado un
"documento en el que defiende que la mujer pueda decidir libremente durante las primeras 14 semanas de embarazo si quiere abortar e introduce un criterio socio- económico hasta la semana 22 para resolver el <vacío legal> de la legislación actual y evitar fraudes ${ }^{76}$.

La doctrina venía ya pronunciándose al respecto en los últimos años para establecer la legalidad del sistema del Plazo. Por ejemplo, BUSTOS afirma que el sistema de plazos no es inconstitucional "pues no es un desconocimiento del derecho a la vida, problema propio de la tipicidad, sino que se trata de la resolución de una situación de conflicto, cuestión a debatir en la antijuricidad ${ }^{77 "}$.

Al igual MUÑOZ CONDE estima que la legislación española no se pronuncia sobre el comienzo de la vida dependiente a efectos del delito de aborto ni presenta obstáculo legal alguno que impida el acogimiento del sistema del Plazo, establece además, que su implementación supondría "una aproximación entre la regulación legal y la realidad social ${ }^{78}$ ". Esto último viene a constatar que asistimos en la realidad a una práctica enmascarada de aborto libre pero practicado bajo la excusa del grave riesgo para la salud física o psíquica de la gestante, cuando en realidad la mayoría de estas interrupciones tiene más que ver con el bienestar personal de las mujeres, que resulta una excusa más afín al espíritu del plazo que al de indicaciones ${ }^{79}$. Desde el ámbito constitucional, uno de los expertos propuestos para la Subcomisión, (en concreto Javier Pérez Royo, Catedrático de Derecho Constitucional) basa en dos argumentos su opinión a favor de una ley de Plazos; el primero se basa en el principio de igualdad y el segundo es la negación de un conflicto de intereses entre los derechos de la mujer y del nasciturus porque éste último no los tiene ${ }^{80}$.

En este estado de cosas, tras recibir los primeros informes, el Gobierno considera

74 Fundamento Jurídico núm. 7, STC (Pleno), Sentencia núm. 53/1985 de 11 de abril.

75 Informe de la OMS "Manejo de las complicaciones del embarazo y el parto: Guía para obstetrices y médicos”, OMS, 2000, traducción en español publicada en 2002 por la Organización Panamericana de la Salud. A su vez establece que un feto es viable a partir de las 22 semanas de gestación.

76 El País, 22 de Abril de 2008 "Un grupo de expertos en bioética aboga por el aborto libre hasta las 14 semanas".

77 BUStOS RAMÍREZ, J.; Manual de Derecho Penal. Parte Especial.2 ${ }^{a}$ edición aumentada corregida y puesta al día, Editorial Ariel, Barcelona. 1991, P. 45.

78 MUÑOZ CONDE, F.; Derecho Penal. Parte Especial., ob. cit., P. 88.

79 LAURENZO COPELLO, P.; Otra vez sobre el aborto, ob. cit., P. 236.

80 Para más información, consultar El País a 17 de Diciembre de 2008, "Pérez Royo: <En el aborto, sólo es constitucional una ley de plazos $>$ ".

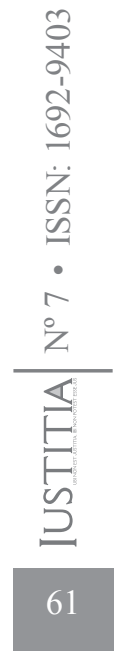


que la "nueva regulación debe combinar plazos- en los que la decisión para abortar sería libre- y, una revisión de los supuestos actuales, de forma que se ponga límite temporal en el supuesto de afección psicológica de la madre ${ }^{81}$ ",en atención a las críticas de fraude de ley. En principio no se tiene establecido ir más allá de la media europea pero sí, por lo menos, la equiparación, al situar un periodo de libre decisión a la mujer que vaya hasta las 12 o 14 primeras semanas de gestación ${ }^{82}$. Tras el Proyecto presentado por el Gobierno ante el Congreso, la Ley de Salud sexual y reproductiva y de la Interrupción voluntaria del embarazo, lleva un tiempo buscando el consenso que lleve a su aprobación con la mayoría más amplia posible. El Consejo de Estado, por ejemplo, se ha pronunciado sobre ello y, tomada en consideración la legislación comparada europea, considera oportuno establecer el plazo en las doce semanas y no en las catorce si lo que se quiere es hacer una legislación homogénea a la europea ${ }^{83}$.

Se establece tras este periodo de libre decisión un plazo de hasta 22 semanas de gestación para supuestos indicados de forma terapéutica o eugenésica. Por tanto, basándonos en los parámetros manejados por la OMS y según un documento presentado por la Sociedad Española de Ginecología y Obstetricia (SEGO) el plazo máximo para abortar son las 24 semanas, pues fuera de ese plazo no es aborto sino "eliminación de un feto viable ${ }^{84 "}$.

El mayor debate estará en acordar, conforme a la viabiliadad fetal, en qué caso por detrás de esas 22 semanas, las mujeres podrán interrumpir su embarazo por grave riesgo para su salud, o por malformaciones del feto.

\section{Las menores de edad que abortan}

La siguiente secuencia pone de manifiesto la evolución del porcentaje de abortos practicados a menores de 19 años en España desde 1998 hasta $2007^{85}$ :

81 El País, 5 de mayo de 2008 "El Gobierno delega en los grupos parlamentarios la nueva ley del aborto. El PSOE propone una Subcomisión en el Congreso para redactar la Reforma”.

82 El País, 11 de Diciembre de 2008, "El Gobierno estudia un plazo para abortar de 12 a 14 semanas".

83 Dictamen de la Comisión permanente del Consejo de Estado aprobado por unanimidad en Sesión celebrada el 17 de septiembre de 2009, p. 31

84 Consultar en CAÑELLAS GALINDO, J.; "La Sociedad Española de Ginecología y Obstetricia (SEGO) ha pedido que el concepto jurídico y legislativo de aborto se adecue al médico" en Revista de Estudiantes de Medicina, http://www.protomedicos.com/2008/07/03/la-sociedad-espanola-deginecologia-y-obstetricia-sego-ha-pedido-que-el-concepto-juridico-y-legislativo-de-aborto-seadecue-al-medico/.

85 Datos del Ministerio de Sanidad, Informe "Interrupción voluntaria del Embarazo. Datos definitivos correspondientes al año 2007”. Tabla EV.1. 
Tabla 2. Abortos en España

\begin{tabular}{|c|c|c|c|c|c|c|c|c|c|}
\hline 1998 & 1999 & 2000 & 2001 & 2002 & 2003 & 2004 & 2005 & 2006 & 2007 \\
\hline $5,71 \%$ & $6,72 \%$ & $7,49 \%$ & $8,29 \%$ & $9,28 \%$ & $9,90 \%$ & $10,57 \%$ & $11,48 \%$ & $12,53 \%$ & $13,79 \%$ \\
\hline
\end{tabular}

Fuente: Ministerio de Sanidad y Consumo

Como las cifras indican, gran parte de las interrupciones voluntarias del embarazo se producen en mujeres menores de edad, por lo que se plantea la posibilidad dentro de los debates del Comité de Expertos y de la Subcomisión parlamentaria que, aunque sean menores de 18 años "puedan interrumpir su embarazo sin autorización de sus padres o tutores a partir de los 14 años, si los médicos consideran que tienen suficiente madurez ${ }^{86}$ ".

El Consejo de Estado también se ha pronunciado sobre la cuestión de las menores de edad y sobre la validez de su consentimiento cuando sea libre e informado y si éste sería válido sin necesidad de la aceptación de los padres, estableciendo al respecto que

\begin{abstract}
"siguiendo una tendencia general en el derecho comparado y en los instrumentos internacionales relativos a la infancia, se ha entendido no sólo que es el interés del menor el que debe prevalecer sobre el de sus padres y tutores en caso de conflicto, y servir de directriz para el ejercicio de la patria potestad o de la tutela, algo ya claro en nuestra legislación civil, sino porque la voluntad del menor debía ser tenida en cuenta al hilo de su madurez ${ }^{87}$ "
\end{abstract}

y para ello el Gobierno pretende reformar la Ley del Paciente (Ley 41/2002 de 14 de noviembre) en su art. 9.5 d) menor con dieciséis años cumplidos. La decisión corresponde a la mujer. Los padres tendrán no obstante derecho a ser informados de la decisión en las condiciones señaladas en los párrafos siguientes. En este sentido el Consejo de Estado entiende que el consentimiento de la mujer de dieciséis años debe considerarse determinante siempre y cuando a ésta se le haya informado previamente $^{88}$.

\title{
Aspectos relativos a la seguridad jurídica
}

Hasta ahora, bajo la aplicación del sistema de Indicaciones se ha puesto de manifiesto la precariedad jurídica a la que se enfrentan las mujeres que alegan la indicación terapéutica en su versión de "peligro para la salud psíquica". Según la

86 El País, 20 de Diciembre de 2008 "El debate sobre la interrupción del embarazo. Una ley del aborto a la europea. Los expertos proponen al Gobierno un plazo de 14 semanas para interrumpir el embarazo sin alegar motivos. Tras las 22 sólo se atenderán casos excepcionales."

87 Dictamen de la Comisión permanente del Consejo de Estado aprobado por unanimidad en Sesión celebrada el 17 de septiembre de 2009, p. 51

88 Dictamen de la Comisión permanente del Consejo de Estado aprobado por unanimidad en Sesión celebrada el 17 de septiembre de 2009, p. 54 
regulación actual, los tribunales tienen plena competencia para entrar a valorar si los requisitos de cada indicación se cumplen escrupulosamente, por lo que algunas mujeres y médicos han sido llamados por la justicia después de una intervención, que fue lo ocurrido en las clínicas del doctor Morín recientemente. En base a la seguridad jurídica de mujeres y médicos se justifican los cambios que en estos meses vienen debatiéndose en el Congreso, pues la aceptación de un periodo de libre decisión implicaría el no sometimiento a requisito alguno que pudiera ser escudriñado a posteriori por los jueces o tribunales.

\section{Notas Finales}

La legalización parcial del aborto llevada a cabo en los años ochenta supuso un paso hacia adelante no sólo en aras a la capacidad de decidir de las mujeres y a su libertad, sino además, en materia de atención sanitaria, es decir, desde la perspectiva de las mujeres el aborto legal supuso un avance en seguridad e higiene que no llevaban aparejados los abortos clandestinos que se practicaban hasta entonces.

Según la regulación actual la práctica del aborto es constitutiva de delito con carácter general, y supone un derecho de las mujeres en el caso de que esté indicado, es decir, justificado bajo tres supuestos. Pero la actual Ley ha dejado de motivar el comportamiento de las mujeres y médicos que alegan circunstancias por encima de la literalidad de los requisitos establecidos en el art. 417 bis $\mathrm{CP}$, es decir, por encima de la legalidad existente. Cuando se crea un delito se hace con una determinada finalidad político criminal, el análisis hoy de la LO 9/1985 desde la política, demuestra que la finalidad con la que se creó la Ley no se cumple. Lo dogmático a día de hoy no debe olvidar ese objetivo político criminal que siguen las leyes penales. Hay que colocar la Ley en la realidad donde va a ser aplicada y según este análisis en el caso del aborto, la realidad supera la norma.

Por eso es importante acomodar la ley del aborto sobre las bases de la sociedad del s. XXI en la que las mujeres han conseguido un marco de libertades que no tenían en los ochenta cuando se aprobó la Ley actual. Además negar la asistencia médica al aborto no significa que el aborto desaparezca ${ }^{89}$. Es por esto que las últimas propuestas de los expertos nos hacen augurar cambios en pro de la visión del derecho a abortar en un intento de homogeneizar nuestra regulación con la de los países europeos. De manera general se apuesta por el sistema de plazos es decir, por un aborto libre hasta el plazo de las 12 semanas, el cual cubriría la mayoría de abortos que se llevan a cabo actualmente en nuestro país y, a partir de las doce semanas, las mujeres en las que concurran ciertos requisitos podrán practicar la interrupción también legal de la gestación sólo si concurren ciertos requisitos, es decir indicaciones.

89 VILlATORO, A.; y ORANICH, M.; Qué es el aborto, ob. cit., p. 16. 
La fuerte apuesta por una política social de prevención y la existencia de una Ley más favorable al aborto libre y voluntario no implica que vayan a aumentar el número de abortos, sino que, por el contrario, conseguirá que éste sea visto como un último recurso. Partimos de la base de lo desagradable de la experiencia, a veces traumática por las secuelas que este tipo de situaciones deja en las mujeres que sufren un proceso de estas características, no tanto por la experiencia en sí, sino por todos los condicionantes sociales que conlleva.

En definitiva la elección del sistema de plazos significa una apuesta por una mayor seguridad jurídica para las mujeres y los médicos y por una mejor atención en la salud reproductiva de las mujeres.

\section{REFERENCIAS}

Bustos Ramírez, J.; Manual de Derecho Penal. Parte Especial. $2^{a}$ edición aumentada, corregida y puesta al día, Editorial Ariel, Barcelona. 1991.

Calvo-Álvarez, J.; Aborto y Derecho. Consideraciones críticas en torno a la doctrina del Tribunal Constitucional, Instituto de Ciencias para la familia, Pamplona, 1997.

Cañellas Galindo, J.; "La Sociedad Española de Ginecología y Obstetricia (SEGO) ha pedido que el concepto jurídico y legislativo de aborto se adecue al médico" en Revista de Estudiantes de Medicina, http://www.protomedicos.com/2008/07/03/lasociedad-espanola-de-ginecologia-y-obstetricia-sego-ha-pedido-que-el-conceptojuridico-y-legislativo-de-aborto-se-adecue-al-medico/

Cobo Del Rosal, M.; Carbonell Mateu, J. C.; “El aborto en el Código Penal Español" en Criminología y Derecho Penal al servicio de la reforma. Libro Homenaje al Profesor Antonio Berinstáin, Instituto Vasco de Criminología, San Sebastián, 1989.

Cuello Calón, E.; Tres temas penales: El aborto criminal; el problema penal de la eutanasia; el aspecto penal de la fecundación artificial. Publicaciones del Seminario de Derecho Penal y Criminología de la Universidad de Barcelona, Bosch, Barcelona, 1955.

Cuerda Arnau, M. L.; "Tratamiento jurídico penal del aborto consentido", en Congreso nacional de la Unión Progresista de Fiscales, en http://www.upfiscales. com/info/estudios/03.htm

Díez Ripollés, J. L.; “El aborto en el Código Penal Español” en Criminología y Derecho Penal al servicio de la reforma. Libro Homenaje al Profesor Antonio Berinstáin, Instituto Vasco de Criminología, San Sebastián, 1989

Esteban, M.; Diario médico, a 27 de Octubre de 2008, "La modificación de la Ley del Aborto. Una reforma necesaria por el fracaso de una Ley”, en http://www. diariomedico.com/edicion/diario_medico/normativa/es/desarrollo/1178329.html 
González Rus, J. J.; "El Aborto”, en COBO DEL ROSAL, M.; (Coord.), Derecho Penal Español. Parte Especial, $2^{a}$ edición revisada y puesta al día con las últimas reformas, Dykinson, Madrid, 2005.

Gimbernat, E.; Diario El Mundo a 10 de julio de 2004 "Los nuevos gestores de la moral colectiva"

Groizard, A.; Gómez de la Serna, El Código Penal de 1870. Concordado y Comentado. $2^{\text {a }}$ ed. corregida y aumentada. Madrid, 1912.

Hernández Rodríguez, G.; El aborto en España. Análisis de un proceso sociopolitico. Universidad Pontificia Comillas, Madrid, 1992.

Islas de González Mariscal, O.; "Evolución del aborto en México", en Boletín Mexicano de Derecho Comparado, nueva serie, año XLI, núm. 123, SeptiembreDiciembre de 2008,

Jiménez de Asúa, L.; El Estado de Necesidad en materia penal. Con especiales referencias a las legislaciones española y argentina, Buenos Aires, 1922

Landrove Díaz, G.; Politica Criminal del aborto, Bosch, Barcelona, 1976.

Lascuraín Sánchez, J. A.; "Del Aborto" en RODRÍGUEZ MOURULLO, G. (Director) y Jorge Barreiro, A.; (Coord), Comentarios al Código Penal, ed. Civitas, Madrid, 1997.

Laurenzo Copello, P.; El fundamento de las indicaciones en el aborto, ed. Universidad Complutense de Madrid, Madrid, 1990.

"Otra vez sobre el aborto: el inevitable camino hacia un sistema de plazos", en Teoría y Derecho: revista del pensamiento jurídico, núm. 3, 2008.

Muñoz Conde, F.; Derecho Penal. Parte Especial. Décimo sexta edición revisada y puesta al día, Tirant Lo Blanch, Valencia, 2007.

Portero Henares, M.; "Del aborto" en ARROYO ZAPATERO, L.; BERDUGO GÓMEZ DE La Torre, I. y otros (Directores), Comentarios al Código penal, Iustel, Madrid, 2007.

Romeo Casabona, C. M.; El Derecho y la bioética ante los límites de la vida humana. Ed. Centro de Estudios Ramón Areces. Madrid, 1994.

Estudios de Derecho Penal. Los delitos contra la vida y la integridad personal y los relativos a la manipulación genética, Comares, Granada, 2004,

Rodríguez Devesa, J. M.; y Serrano Gómez, A.; Derecho Penal Español. Parte Especial, Decimoséptima edición, Dykinson, Madrid, 1994.

Silva Sánchez, J. M.; "Los indeseados como enemigos. La exclusión de seres humanos del status personae" en Revista Electrónica de Ciencia Penal y Criminología, núm. 9, 1, 2007.

Villatoro, A. y Oranich, M.; Qué es el aborto, en Biblioteca Salud y Sociedad, Barcelona, 1977. 